\title{
Reading Practices of EFL Students: A Survey of Kuwaiti College Students
}

\author{
Abdus Sattar Chaudhry ${ }^{1} \&$ Amel Al-Adwani ${ }^{2}$ \\ ${ }^{1}$ Department of Information Studies, Kuwait University, Kuwait \\ ${ }^{2}$ English Language Department, College of Basic Education; Public Authority for Applied Education (PAAET), \\ Kuwait \\ Correspondence: Abdus Sattar Chaudhry, Department of Information Studies, Kuwait University, Kuwait.
}

Received: March 8, 2019 Accepted: April 15, 2019 Online Published: April 17, 2019

doi: 10.5539/elt.v12n5p130 URL: https://doi.org/10.5539/elt.v12n5p130

\begin{abstract}
Reading is important for students by contributing significantly to success in their studies and their career development. A questionnaire-based survey was conducted in the English Department of the College of Basic Education, Public Authority for Applied Education and Training (PAAET), in Kuwait. Based on 410 responses of EFL college students in Kuwait on their reading practices, it was found that students read mainly for entertainment, and reading does not appear to be a popular activity among students. Fiction, fashion, and best sellers were the three main types of reading, indicating that academic reading was not a priority. Only a small proportion of students used e-books. Most students perceived such features of e-books as their portability and ability to store more information as likely to attract more students to e-reading, and indicated that they would be attracted to reading e-books themselves if circumstances change. This indicates a good potential to promote e-reading among students if steps are taken to make e-books and e-readers available to them through libraries and academic institutions. E-reading is also expected to become more popular among students if it could be linked to academic reading, particularly to the availability of text books in e-format. Libraries in Kuwait should start more proactive program to promote e-books and e-reading among college and university students.
\end{abstract}

Keywords: EFL students, E-reading, E-books, reading trends, Kuwait

\section{Introduction}

Reading is a process, a mode of thinking, and an experience that involves many complex skills. Anderson and Pearson (1984) consider reading a cornerstone for success throughout the life of an individual. Kirsch and Guthrie (1984) assert that reading contributes significantly to job success, career development, and the ability to respond to change. Baron (2015) stated that the amount of time spent in engagement with electronic media was on the increase. It is therefore expected that students growing up in the digital information era will do more reading. Increases in the availability of e-books are also expected to make reading more popular, as e-books have numerous advantages over printed books, including remote access, portability and up-to-date information (Hernon, Hopper, Leach, Saunders, \& Zhang, 2007). Zipke (2013) also highlighted the many advantages of e-readers over traditional books. Larson (2015) discussed the learning potential of e-books and pointed out that e-book technology affords readers new possibilities of controlling text to meet individual needs. Digital texts come in different forms with multimodal features such as hyperlinks, audio, video, and images, all of which will impact the growth of reading. It is expected that students will be attracted to electronic books more than printed books.

Studies, however, have also warned of the negative aspects of e-books. Spencer (2006) reported negative aspects of e-reading in an academic setting. Akbar, Taqi, Dashti, and Sadeq (2015) investigated e-reading usage as opposed to traditional book reading in Kuwait and highlighted the fact that e-reading may accelerate students' reading rate and progress, but they also cautioned that there might be a lower level of comprehension when reading e-resources. The authors concluded that students' attitudes toward e-reading tended to be less positive than toward conventional book reading. Studies across subject areas have indicated important reasons to identify and test assumptions about reading preferences with larger and more diverse samples from different cultural contexts. 
This study investigated reading practices of students from the Department of English as Foreign Language (EFL) in the College of Basic Education at the Public Authority for Applied Education and Training (PAAET) in Kuwait. The first part of the study explored reading practices related to print or traditional material to investigate what motivated the students to read and their preferences in where to obtain books, where they preferred to read, and what types of reading material they preferred. The second part of the study covered e-reading, focusing on their awareness of and attitudes toward the features, limitations, and potential of e-books and e-readers. The results of this study are expected to help in taking steps to enhance reading among students in higher educational institutions.

\section{Literature Review}

Studies suggest that if young people start experiencing the joy of reading, they will become life-long readers. The National Endowment for the Arts [NEA] $(2008,2009)$ reported that although reading as a leisure activity had dramatically declined over the course of 20 years, it had marginally increased again by 2009 . Although there was a reversal in the downward trend, the percentage of 18- to 24-year-olds who had read a book in 2008 was still significantly lower than it was a quarter century before.

Dewan (2013) suggests that reading matters for a number of reasons. The college years may be one of the most important times to read. Dewan (2015) highlights that those who develop the habit of reading have a greater likelihood of success in their immediate and long-term future. NEA $(2008,2009)$ studies also agree that those who read books are more likely to participate in volunteer work, play sports, attend sporting events, engage in outdoor activities, attend cultural events, visit museums, attain higher levels of education, and work in more financially rewarding jobs. Reading also increases cognitive skills and the likelihood of student success. The more people read for pleasure, the greater their intellectual development (Krashen, 2008).

Huang, Capps, Blacklock, and Garza (2014) pointed out that college students were reading material from social media sites far more than from books, and in particular about twice as much material from social media sites as from leisure books. They noted that books for pleasure were being supplanted by Facebook and Twitter posts. Dewan (2015) warns that it is important is that students turn to books as readily as they do blog posts or newspaper articles and notes that a large percentage of the written word is available in book form.

With the continuing addition of electronic texts in colleges and universities, increasing attention has come to be paid to e-books and their impact on learning. Anderson (2003) surveyed 1500 US online internet users and reported that the more frequently the users used the internet, the more positively they rated e-books. Wilson (2003) reported that there was empirical evidence that once students are connected to e-devices they start enjoying e-reading and read faster. Armatus, Holt, and Rice (2003) compared approaches between on-campus and off-campus students. The off-campus students used electronic resources more often and attached greater value to them. They suggested that learner characteristics that might differentiate these two groups need to be analyzed and taken into consideration when designing learning environments while preserving overarching pedagogical goals.

Also, many researchers pointed out that younger users seem to prefer e-books to print-based learning resources, that e-book capabilities will continually improve, and that their costs will likely decrease in the future (Chang \& Ley, 2006; Li Liew, Foo, \& Chennupati, 2000; Temple, Kemp, \& Benson, 2006). Hernon et al. (2007) pointed out that e-book reading in higher education has numerous advantages, particularly the access it affords to a wide variety of reading sources and to up-to-date reading material. Rowlands, Nicholas, Jamali, and Huntington (2007) reported that although e-books compared unfavorably in perceived ease of reading, they offered some benefits, including ease of copying, currency, and availability.

The factors reported in the above studies suggest that e-books will be accepted more in the future. On the other hand, problems associated with e-books and other onscreen text-based materials have been noted in the literature Evans, Charland, and Saint-Aubin (2009) suggest that reading from a digital platform is characterized by more time spent on browsing and scanning, keyboard spotting, and more selective one-time reading, and less time spent on in-depth reading and concentered reading. Abdullah and Gibb $(2008,2009)$ conducted a series of studies investigating e-book usability issues. The first study surveyed students in Scottish higher education institutions about e-book usage, and the second study explored students' attitudes regarding e-book use. These studies indicated that students used e-books for selective reading and reference purposes.

Rho and Gedeon (2000) interviewed graduate students and found that when encountering screen-based material, the students usually skimmed the materials first but preferred to print out the relevant and important parts of the text for further reading. Evans et al. (2009) found that digital readers' jump from platform is slower than reading from printed text. It was concluded that although the current cohort of undergraduate students belongs to the 
tech-savvy "millennial" generation, there is conflicting evidence regarding students' acceptance of e- books. We thus recognize a discrepancy in the findings in the literature that at a fundamental level reflects differences in opinion about the purpose of learning and therefore the formulation of an appropriate learning theory. In summary, readers tend to use e-books for browsing but not for intensive reading.

While the advantages of using e-books in academic institutions are still debated, the effects of using e-books in either first or second language classroom have been better defined. E-books have been found to support language learners and motivate reluctant or young learners (Day \& Bamford, 2002). Other studies pointed out that reading-supportive devices, which provide glossaries and the pronunciation of unfamiliar words, can be accessed more easily through e-texts than hard copy materials (Chen \& Yen, 2013). Chou (2012) noted that e-books seem more acceptable for pleasure reading than intensive study, and added that the greatest use of e-books in academia is in the area of computer science, engineering, business management, and the social sciences. Only a few studies have examined college students or students with English as a foreign or second language.

Arnold (2009) conducted an online extensive reading program on advanced learners of German as a foreign language, concluding that learners experienced a variety of effective and linguistic benefits. There was also evidence that the study participants developed into skilled second language readers, making conscious decisions about reading strategy and dictionary use. Another study by Cheng (2016) explored 32 foreign language university learners in the USA in an online reading strategy survey, revealing that the students demonstrated higher-order cognitive abilities in locating resources, evaluating reading materials, making decisions, and adjusting their reading speed.

Haung (2013) investigated 67 first-year university students in Taiwan taking EFL reading courses. During the year-long experiment, students read at least one online e-book weekly from the reading list provided by the researcher. The students provided positive feedback on the program's strategy tools and its learning effects. They pointed out e-books' potential to cultivate better reading habits and increase motivation; they also perceived e-books as being more available, portable, and eco-friendly than print-based texts. However, students also noted difficulties with e-book reading in terms of eyestrain and dealing with lengthy texts. Even though these studies provide useful information for educators and teachers designing an e-book reading program or e-reading sites, these studies focused mainly on students' perceptions of the program. There is still a need to understand EFL students' opinions of reading e-books rather than of a specific program and in different EFL settings.

In a recent study, Akbar et al. (2015) surveyed 40 freshman female students studying in the College of Basic Education in the English department, PAAET, Kuwait. Data drawn from students' writing diaries together with two questionnaires were analyzed both quantitatively and qualitatively. Their findings indicated that e-reading might accelerate the students' reading rate and progress, which might be due to reading application features that train the students to practice reading faster. On the other hand, the students reported lower comprehension levels when they read from an e-resource, and their attitudes toward e-reading tend to be less positive than toward conventional book reading.

Our review of previous studies indicates that considerable research has been carried out on reading habits and trends in reading. Also, numerous projects have been conducted on e-reading and e-readers. These studies were helpful in developing the data collection instrument of our study and were of benefit in developing the introduction and research focus of our project. However, only a few studies could be found that surveyed reading habits and preferences in Kuwait. Therefore, this study is intended to survey students' reading habits as well as their perceptions regarding e- book use in college-level EFL courses. This paper explores the use and preference of reading and e-reading in a full academic year 2018-2019 among the English Department students of the College of Basic Education in Kuwait.

\section{Methodology}

A survey method of research was used for this study in which data were collected using a questionnaire. This methodology is in line with the approaches of similar studies (Florence, Adesola, Alba, \& Adewumi, 2017; Foasberg, 2011). The data collection instruments used in previous studies were helpful in designing the questionnaire for this study (Chen, Fan, \& He, 2012; UCLA, 2011).

The questionnaire consisted of two parts; part one has seven questions on traditional reading, part two nine questions on e-readings. A copy of the questionnaire is given as Appendix A at the end of the paper.

The questionnaire was distributed to a total of 450 students in the English Department of the College of Basic Education, Public Authority for Applied Education and Training (PAAET) in Kuwait. At the time of the study, these students were enrolled in different levels of courses from first to fourth year. These included courses on 
reading, error analysis, and teaching English as a Foreign Language. A total of 410 completed questionnaires were received (response rate of 91.1\%). All students were female, since there was no English department for male students in the College of Basic Education at PAAET in Kuwait.

\section{Findings}

\subsection{Reading Activities}

Reading practices are affected by the perceived benefits of reading. We asked students about their motivation for reading. A majority of them (34.1\%) reported that they read books for entertainment, followed by reading for academic purposes (32.6\%) and to gain knowledge (25.5\%). A summary of their responses is given in Table 1 .

Table 1. Motivations for reading

\begin{tabular}{llll}
\hline$\#$ & Reason & Frequency & Percentage \\
\hline 1 & Entertainment & 140 & 34.1 \\
2 & Academic & 134 & 32.6 \\
3 & Knowledge & 105 & 25.5 \\
4 & Work & 12 & 2.9 \\
5 & Other & 20 & 4.9 \\
6 & Total & 411 & 100 \\
\hline
\end{tabular}

We also asked students from where they obtain books to read. A majority responded that they bought the books (68.4\%) that they read, while $19.7 \%$ used books available for free online. Borrowing books from libraries was not common; less than 10 per cent of the respondents chose this option. The sources of their books for reading are listed in Table 2.

Table 2. Sources of books

\begin{tabular}{llll}
\hline$\#$ & Source & Frequency & Percentage \\
\hline 1 & Buying & 281 & 68.4 \\
2 & Free online & 81 & 19.7 \\
3 & Borrowing from libraries & 39 & 9.5 \\
4 & Friends & 81 & 19.7 \\
5 & Others & 10 & 2.4 \\
6 & Total & 411 & 100 \\
\hline
\end{tabular}

We also asked students about their favorite places to read. More than $75 \%$ of the students participating in the study responded that they preferred to read at home. About $12 \%$ read at a library, while $2.8 \%$ read when they are traveling.

Table 3. Preferences for reading place

\begin{tabular}{llll}
\hline$\#$ & Place & Frequency & Percentage \\
\hline 1 & Home & 309 & 75.2 \\
2 & Coffee shop & 48 & 11.7 \\
3 & Library & 32 & 7.8 \\
4 & At work & 12 & 2.9 \\
5 & During travel & 10 & 2.8 \\
6 & Total & 411 & 100 \\
\hline
\end{tabular}


As to language, $48 \%$ read books in both Arabic and English, 30\% only in Arabic, and 21\% only in English. Also, $38 \%$ read magazines. A large majority of those who like to read $(78 \%)$ stated that they enjoy reading. However, reading does not appear to be a popular activity among students. Of the students who responded that they read, only about $25 \%$ indicated that they read frequently, and more than $56 \%$ responded that they only read sometimes.

\subsection{Types of Reading Material}

We asked the students what types of material they read. They read a variety of types of books; fiction, fashion, and best sellers were the three main types they reported reading. The types of books popular with students are listed are presented in Table 4.

Table 4. Types of books read

\begin{tabular}{llll}
\hline$\#$ & Type of Books & Frequency & Percentage \\
\hline 1 & Fiction & 164 & 39.9 \\
2 & Best sellers & 49 & 11.9 \\
3 & Fashion & 45 & 10.9 \\
4 & Literary works & 38 & 9.2 \\
5 & Recommended & 22 & 5.4 \\
6 & Art and culture & 21 & 5.1 \\
7 & Biographies & 18 & 4.4 \\
8 & Socioeconomic & 13 & 3.2 \\
9 & Hobbies & 8 & 1.9 \\
10 & Housekeeping & 6 & 1.5 \\
11 & Travel \& Tourism & 5 & 1.2 \\
12 & Other & 22 & 5.4 \\
13 & Total & 411 & 100 \\
\hline
\end{tabular}

As shown in Table 4, their academic reading is limited; the figures indicate a greater motivation to read fiction and best sellers.

\subsection{E-Reading}

More than 60 per cent of the respondents stated that they also read e-books. More than 90 per cent of those who reported that they engage in e-reading stated that they used mobile devices and iPads; only 10 per cent reported that they used dedicated e-readers.

Of the 410 who responded to the questionnaire, $32 \%$ responded that did e-reading only rarely, about $24 \%$ stated they never did e-reading, and another $24 \%$ stated that they did e-reading sometimes.

When asked how much of their reading was on e-readers, more than $39 \%$ said their e-reading made up less than one-third of their total reading and about 30\% stated that their readings only included a few e-books. More than $51 \%$ said that most of their e-reading was class reading.

\subsection{Perceptions of Benefits and Drawbacks}

We asked students about their perceptions of the main benefits and drawbacks of e-books and e-readers. We listed several possibilities and asked students to respond to them along a Likert scale.

Students were also asked what features they thought would be discouraging factors in promoting e-reading among students. Seven factors were presented in the questionnaire for them to rate on a scale of 1 to 5 ; these features were chosen from previous studies of e-reading. We also asked the students how valuable the e-book features are for their interest in e-reading and sought their feedback about the potential of e-reading in making learning and teaching more effective. They rated the value of selected features on a scale of 1 to 5 ( 1 being very valuable and 5 not valuable). Their responses are summarized in Table 5. 
Table 5. Value of E-reader features

\begin{tabular}{lllllll}
\hline$\#$ & Feature & Very valuable & Valuable & Moderate & Less valuable & Not valuable \\
\hline 1 & Portability & 240 & 64 & 35 & 20 & 52 \\
2 & Ability to store more information & 237 & 62 & 44 & 30 & 38 \\
3 & Access to a large collection & 56 & 58 & 204 & 51 & 42 \\
4 & Convenience & 50 & 234 & 58 & 39 & 28 \\
5 & Text-speech capability & 49 & 30 & 75 & 188 & 60 \\
6 & Special functions & 41 & 64 & 229 & - & - \\
\hline
\end{tabular}

As shown in Table 5, respondents of this study considered the portability and ability to store more information as the top two features of e-books that might attract more readers.

We also asked the students about possible discouraging factors. Their rankings are summarized in Table 6 . Because of the low numbers for e-reading and ownership of e-readers, the remaining discussion concerns the opinions of respondents on e-reading.

Table 6. Discouraging factors

\begin{tabular}{|c|c|c|c|c|c|c|}
\hline \# & Feature & Very distracting & Distracting & Moderate & Less distracting & Not distracting \\
\hline 1 & Eyestrain & 244 & 20 & 80 & 41 & 26 \\
\hline 2 & Limited selection & 223 & 45 & 69 & 38 & 36 \\
\hline 3 & Cost of e-readers & 78 & 44 & 218 & 28 & 43 \\
\hline 4 & Cost of e-books & 70 & 47 & 44 & 35 & 247 \\
\hline 5 & Privacy concerns & 51 & 25 & 263 & 66 & 6 \\
\hline 6 & User interface & 39 & 41 & 82 & 227 & 23 \\
\hline 7 & Preferences for printed books & 18 & 230 & 71 & 81 & 11 \\
\hline
\end{tabular}

As shown in Table 6, students appeared to be concerned about the possible eyestrain that e-readers and e-books might have on the reader, as 244 out of 410 rated this the most distracting feature. Second on the list was the limited selection and availability of books in e-format, as 223 out of 410 respondents rated it highly.

Since the number of respondents reading e-books was small, we focused on their feedback concerning their perceptions rather than their actual use of e-books.

Table 7. Perceptions of the helpfulness of E-books

\begin{tabular}{llll}
\hline$\#$ & Parameter & Frequency & Percentage \\
\hline 1 & Quite helpful & 130 & 31.6 \\
2 & Helpful & 130 & 31.6 \\
3 & Most helpful & 110 & 26.8 \\
4 & Less helpful & 25 & 6.1 \\
5 & Least helpful & 16 & 3.9 \\
6 & Total & 411 & 100 \\
\hline
\end{tabular}

As shown in Table 7, more than $62 \%$ of the respondents considered e-books helpful or quite helpful, and more than $26 \%$ rated e-books as most helpful. Thus, a majority of students $(90 \%)$ who participated in this study perceived e-books as helpful. This is an encouraging sign.

We also asked the students about their satisfaction with e-books, and as expected a large number (36\%) remained 
neutral. This could because most were not reading e-books at the time of the study. But those who were reading e-books appeared to be satisfied, as more than $32 \%$ were either most satisfied or quite satisfied. Their satisfaction levels are shown in Table 8.

Table 8. Satisfaction with E-Books

\begin{tabular}{llll}
\hline$\#$ & Parameter & Frequency & Percentage \\
\hline 1 & Most satisfied & 65 & 15.8 \\
2 & Quite satisfied & 68 & 16.5 \\
3 & Neutral & 148 & 36.0 \\
4 & Less satisfied & 73 & 17.8 \\
5 & Least satisfied & 57 & 13.9 \\
6 & Total & 411 & 100.0 \\
\hline
\end{tabular}

Students who did not read e-books for any reason were also asked whether they would be attracted to read e-books if circumstances changed (meaning a more attractive situation become prevalent). Five possible scenarios were listed in the questions for them to indicate their agreement. A summary of their responses is given in Table 9.

Table 9. Circumstances for E-Reading

\begin{tabular}{llll}
\hline$\#$ & Parameter & Frequency & Percentage \\
\hline 1 & E-reader features become more user friendly & 163 & 39.7 \\
2 & E-books are used as text reading & 77 & 18.7 \\
3 & E-books become available from the library & 55 & 13.4 \\
4 & Providers give clear instructions and information & 44 & 10.7 \\
5 & Other & 7 & 1.7 \\
6 & Total & 411 & 100.0 \\
\hline
\end{tabular}

As shown in Table 9, students appear to be willing to shift to e-reading if the features of e-readers become more user-friendly.

We also asked students if they would be willing to acquire e-books in the future. They were asked to give their opinion for four options. A summary of their responses in given in Table 10.

Table 10. Acquisition of E-Books in the Future

\begin{tabular}{llll}
\hline$\#$ & Parameter & Frequency & Percentage \\
\hline 1 & Within a year or two & 127 & 30.9 \\
2 & Before I graduate & 87 & 21.2 \\
3 & Not until I graduate & 63 & 15.3 \\
4 & Not sure & 134 & 32.6 \\
5 & Total & 411 & 100.0 \\
\hline
\end{tabular}

As shown in Table 10, more than $66 \%$ indicated the possibility of acquiring books in the future. About $30 \%$ expected to acquire e-books in a year or two, while about $32 \%$ expect to acquire e-books after they graduate. More than $32 \%$ stated that they were not sure if they would like to acquire e-books.

\section{Discussion}

As reported in Tables 1, 2, and 3, a majority of students read books for entertainment; a majority of them did their 
reading at home, and most of them bought the books they read. These findings show that reading culture is very prevalent. Kuwait has a country-wide system of public libraries, and the libraries in its educational institutions have good financial support for the acquisition of reading materials. It appears that there is a need for initiatives to promote reading and libraries ought to take steps to publicize their resources and services. As shown in Table 4, of those who were reading, about 40 per cent of them were reading fiction. Academic reading and reading to gain knowledge about socio-economic and practical topics were very low. This is particularly surprising as the 410 students who participated in the study were from a college, in particular from its English language department, and were taking English language courses at the time of the study. This might be an indication that academic institutions have not integrated reading into their learning and teaching activities. Special efforts should be made by academic institutions to encourage students to read. In the College of Basic Education (CBE) in Kuwait, students are enrolled in a 4-year English program to earn a bachelor's degree in teaching English as a foreign language at the primary school level. One of the basic objectives of the English department and the EFL reading course is to prepare students to read the professional and academic material written in the target language (English) in their fields of study (Al Darwish \& Akbar, 2013).

The reading habits of Kuwaiti students are not in line with the world trends. For example, Florence et al. (2017) reported that more than $65 \%$ students they survey reported that love to read from their various fields of specialization on a daily basis. Their study confirmed that good reading habits enhance academic performance. The recommendation that they made will be helpful for colleges in Kuwait. This study suggested that courses on communication skills for the first year students should put an emphasis on prose work and fiction

Tables 5 to 10 present findings about the perceptions and attitudes of respondents toward e-reading and e-readers, and about the potential of e-books to support learning and teaching in colleges. As reported in Table 5, respondents attached a great value to portability and the ability to store information, as 240 and 237 participants, respectively, considered these features very valuable. This shows that if steps are taken to promote e-reading, students appear to be ready to leverage the attractive features of e-readers. This appears to be consistent with international trends. In a study of the adoption of e-readers in Australia, Foasberg (2011) found that the positive features of e-readers were ranked as follows: portability, convenience, storage, special functions, and text-to-speech.

Table 6 reveals very interesting facts. While a large number of respondents (244 and 223) considered possible eyestrain and the limited selection of titles of interest in e-book collections to be the main negative factors, they do not seem to be concerned about the user-friendliness of interfaces or high cost of e-books. This might be linked to the fact that most Kuwaiti students have access to electronic gadgets, so the use of smart phones and other devices such as iPads and laptops has become routine for them, and being in an affluent society they are not much concerned about the cost of books. Foasberg (2011) reported that price is the greatest barrier to e-reader adoption and that respondents had little interest in borrowing e-reader-compatible e-books from the library.

As shown in Table 7, more than $62 \%$ of the respondents considered e-books helpful or quite helpful, and more than $26 \%$ rated them most helpful; thus, an overwhelming majority of the respondents $(90 \%)$ perceived e-books as helpful. This is an encouraging sign, suggesting that immediate steps should be taken by relevant agencies in Kuwait to make e-books and e-readers available to students. Currently, e-books are available only in private schools in Kuwait. Some smart schools have started using e-books as part of the new curriculum in Kuwait. Chaudhry and Alqattan (2014) reported that students in private Kuwaiti schools enjoyed reading in the electronic medium more than they did the paperback alternative. On the other hand, not many government schools are using e-books. The Ministry of Education tried to introduce the use of tablets in schools instead of printed books, but this project was not successful. One difficulty was that most national curriculum books were not available in e-book format; only English books for primary, secondary, and high school are available in pdf format as e-books.

There appears to be an emphasis on learning the English and Arabic languages in schools. In Kuwait English is consider a compulsory language with Arabic language in schools starting in the first grade. Since 1993 the Kuwaiti Ministry of Education (KMOE) has included English as a compulsory subject in the Kuwaiti government school's curriculum in the primary stage alongside the Arabic language (Al-Adwani, 2005; Al Darwish, 2006).

As shown in Table 8, most respondents were neutral with regard to their satisfaction with the features of e-books. This could be because only a very small number of students were using e-books at the time of the study. Tables 9 and 10 indicate that more than 50 per cent of the respondents indicated that they would be willing to shift to e-reading if circumstances changed in the availability of e-books and e-readers. This is an encouraging sign for promoting the use of e-books. There is a need for libraries in Kuwait to start more proactive campaign for 
promotion of e-books and e-readers.

Concerns have also been raised that despite the high standard of living in Kuwait, the country is falling behind because of its relatively poor innovation and productive capabilities (Al Kharang \& Ghinea, 2013). Al Darwish and Akbar (2013) also expressed concern regarding the poor levels of student performance. They stated that many students in Kuwaiti public elementary schools reach certain grade levels without the ability to read well. They also commented that students' academic reading lags as a result. They rightly point out that for the most part, reading instruction in college and university ESL and EFL courses tends to focus on comprehending the language of the texts. Al Kharang and Ghinea (2013) highlighted a lack of awareness of the potential benefits of creating an e-learning culture in which technology is a facilitator.

A recent study by Al-Adwani (2005) reported that Kuwaiti students hold favorable attitudes toward both leisure and academic reading. Younger students showed more positive attitudes toward reading. However, having an account on Instagram, Snapchat, or YouTube and possessing a smart device had negative effects on attitudes towards reading (Al-Adwani and Al-Fadley (2017). The findings of this study corroborate their results and should contribute to promoting reading and e-reading to enhance learning in Kuwaiti educational institutions.

\section{Conclusions and Recommendations}

Reading is important for students as it contributes significantly to their success in their studies and to their career development. Our analysis of reading practices of Kuwaiti students indicates that they read mainly for entertainment. A majority of the students who participated in the study reported that they bought the books that they read. Most of them preferred to read at home. A very small number of students listed libraries as their source of choice to access books. About half of the students surveyed indicated both Arabic and English as their preferred languages for reading. However, reading does not appear to be a popular activity among students, as only one-quarter of those who were readers read frequently, while the others read only occasionally. Fiction, fashion, and best sellers were the three main types of reading, indicating that academic reading was not a priority for them.

Only a small proportion of students who participated in the study were using e-books when this study was conducted. However, they appeared to be convinced of the importance of e-reading, as a majority of them indicated their possible shift to e-reading because of several attractive features of e-books. It was interesting to note that unlike reading traditional and printed books, most of the students preferred reading e-books for class. Most students perceived that such features of e-books as portability and the ability to store more information would attract more students to e-reading. They appeared to be concerned about two discouraging factors in particular, possible eyestrain and the limited selection of e-resources.

Students indicated that they would be attracted to reading e-books if circumstances changed, particularly if the features of e-readers become more user-friendly. They also seemed to be willing to acquire e-books in the future. They expressed their interest in acquiring e-books in a year or two or after they graduate. This shows a good potential to promote e-reading among students if steps are taken to make e-books and e-readers available to them through libraries and their academic institutions. E-reading is also expected to become more popular among students if linked to academic reading, particularly to the availability of text books in e-format.

This study clearly indicates that there is a need for libraries and academic institutions to take steps to promote e-reading, link it to academic work, and make more e-books and e-readers available. However, since this study is based only on a survey of students, follow-up studies involving faculty and applying qualitative methods are recommended to further investigate reading and e-reading preferences. Interviews and focus group discussions will yield richer data that will be useful in building programs to promote reading and e-reading among Kuwaiti students.

\section{Acknowledgments}

We are thankful to the English department, faculty and management of the College of Basic Education, Public Authority of Applied Education and Training, Kuwait for their cooperation in the conduct of the study.

\section{References}

Abdullah, N., \& Gibb, F. (2008). Students' attitudes toward e-books in a Scottish higher education institutes: Part 1. Library Review, 57(8), 593-605. https://doi.org/10.1108/00242530810899577

Abdullah, N., \& Gibb, F. (2009). Students' attitudes toward e-books in a Scottish higher education institute: Part 3. Search and browse tasks. Library Review, 58(1), 17-27. https://doi.org/10.1108/00242530910928906

Akbar, R., Taqi, H., Dashti, A., \& Sadeq, T. (2015). Does e-reading enhance reading fluency? English Language Teaching, 8(5), 195-207. https://doi.org/10.5539/elt.v8n5p195 
Al Adwani, A. (2005). Factors contributing to student language learning difficulties in the College of Basic Education in Kuwait (unpublished doctoral dissertation). University of Newcastle upon Tyne, Newcastle UK.

Al-Adwani, A., \& Al-Fadley, A. (2017). The attitudes of fifth and sixth graders in Kuwait governmental schools towards recreational and academic reading in English. English Language Teaching, 10(12), 37-49. https://doi.org/10.5539/elt.v10n12p37

Al Darwish, S. (2006). An investigation of teachers' perceptions of the English language curriculum in Kuwaiti elementary schools (unpublished doctoral dissertation). University of Denver, Denver, Colorado, USA.

Al Darwish, S., \& Akbar, R. (2013) EFL reading motivations: Evidence from Kuwait. Journal of Education and Practice, 4(28), 203-211.

Al Kharang, M., \& Ghinea, G. (2013). E-learning in higher educational institutions in Kuwait: Experiences and challenges. International Journal of Advanced Computer Science and Application, 4(4), 1-7.

Anderson, N. J. (2003). Scrolling, clicking and reading English: Online reading strategies in a second/foreign language. The Reading Matrix, 3(3), 1-33.

Anderson R., \& Pearson P. D. (1984). Schema-theoretic view of basic processes in reading comprehension. Handbook of reading research (pp. 255-291). New York: Longman.

Armatus, C., Holt, D., \& Rice, M. (2003). Impacts of an on-line supported and resource-based learning environment: Does one size fit all? Distance Education, 24(2), 140-158.

Arnold, N. (2009). Online extensive reading for advanced foreign language learners: An evaluation study. Foreign language Annals, 42(2), 340-366. https://doi.org/10.1111/j.1944-9720.2009.01024.x

Baron N. (2015). Words on screen: The fate of reading in a digital world. Oxford, New York: Oxford University Press.

Chang, S. L., \& Ley, K. (2006). A learning strategy to compensate for cognitive overload in online learning: Learner use of printed online materials. Journal of Interactive Online Learning, 5(1), 104-117.

Chaudhry, A., \& Alqattan, N. (2014). Student response to e-books: Study of attitude toward reading among elementary school children in Kuwait. The Electronic Library, 32(1), 458-472. https://doi.org/10.1108/EL04-2012-0041

Chen, Y.-L., Fan, S., \& He, Z. (2012). Exploratory research: The effects of electronic books on college students. MBA Student Scholarship, Paper 14. Retrieved from http://scholarsarchive.jwu.edu/mba_student/14

Chen, I.-J., \& Yen, J.-C. (2013). Hypertext annotation: Effects of presentation formats and learner proficiency on reading comprehension and vocabulary learning in foreign languages. Computers \& Education, 63, 416-423. https://doi.org/10.1016/j.compedu.2013.01.005

Cheng, R. T. (2016). Reading online in foreign languages. A study of strategy use. International Review of Research in open and distributed learning, 17(6), 164-182.

Chou, I.-C. (2012). Understanding on-screen reading behaviors in academic contexts: A case study of five graduate English-as-a-second-language students. Computer Assisted Language learning, 25(5), 416-433.

Day, R., \& Bamford, J. (2002). Top ten principles for teaching extensive reading. Reading in a Foreign Language, 14(2), 136-141.

Dewan, P. (2013). Reading matters in the academic library: Taking the lead from public librarians. Reference \& User Services Quarterly, 52(4), 311. https://doi.org/10.5860/rusq.52n4.309

Dewan, P. (2015). Reading trends and college-age students: The research, the issues, and the role of libraries. Against the Grain, 27(1). https://doi.org/10.7771/2380-176X.6993

Evans, M. A., Charland, A. R., \& Saint-Aubin, J. (2009). A new look at an old format: Eye-tracking studies of shared book reading and implications for ebook research. In G. Bus, \& S. Neuman (Eds), Multimedia and literacy development (pp. 89-111). New York: Routledge.

Florence, F. O., Adesola, O. A., Alba, H. B., \& Adewumi, O. M. (2017). A survey on the reading habits among colleges of education students in the Information Age. Journal of Education and Practice, 8(8), 106-110.

Foasberg, N. M. (2011). Adoption of e-book readers among college students: A survey. Information Technology and Libraries, 30(3). https://doi.org/10.6017/ital.v30i3.1769

Hernon, P., Hopper, R., Leach, M. R., Saunders, L. L., \& Zhang, J. (2007). E-books use by students: 
Undergraduates in economics, literature, and nursing. Journal of Academic librarianship, 33(1), 3-13. https://doi.org/10.1016/j.acalib.2006.08.005

Huang, S., Capps, M., Blacklock, J., \& Garza, M. (2014). Reading habits of college students in the United States. Reading Psychology, 35(5), 437-467. https://doi.org/10.1080/02702711.2012.739593

Kirsch, I., \& Guthrie. J. (1984). Adult reading practices for work and leisure. Adult Education Quarterly, 34(4), 213-232. https://doi.org/10.1177/0001848184034004003

Krashen, S. (2008). The Power of reading: Insights from the research. Westport, CT: Libraries Unlimited.

Larson, L. (2015). The learning potential of e-books. Educational Leadership. Retrieved from https://4oops.edublogs.org/files/2016/09/The-Learning-Potential-of-e-Books-Lotta-Larson-267w5cf.pdf

Li, L. C., Foo, S., \& Chennupati, K. (2000). A study of graduate student end-users' use and perception of electronic journals. Online Information Review, 24, 302-315. https://doi.org/10.1108/14684520010350650

National Endowment for the Arts. (2008). Reading at risk: A survey of literary reading in America. Retrieved from http://arts.gov/publications/reading-risk-survey-literary-reading-america-0

National Endowment for the Arts. (2009). To read or not to read: A question of national consequence. Retrieved from http://arts.gov/file/2574

Rho, Y. J., \& Gedeon, T. D. (2000). Academic articles on the web: Reading patterns and formats. International Journal of Human-Computer Interaction, 12, 219-240. https://doi.org/10.1207/S15327590IJHC1202_4

Rowlands, I., Nicholas, D., Jamali, H. R., \& Huntington, P. (2007). What do faculty and students really think about e-books? Aslib Proceedings, 59(6), 489-511. https://doi.org/10.1108/00012530710839588

Temple N. J., Kemp, C., \& Benson, A. (2006). Computer technology and student preferences in a nutrition course. The Journal of Open, Distance and e-Learning, 21(1), 71-77. https://doi.org/10.1080/0268051050 0472262

University of California Libraries. (2011). UC Libraries academic e-book usage survey. Springer E-Book Pilot Project, May 2011.

Wilson, R. (2003). E-book readers in higher education. Journal of Educational Technology Society, 6(4), 8-17.

Zipke, M. (2013). Teachers' thoughts on e-readers in the elementary school classroom. Education and Information Technologies, 18, 421-441. https://doi.org/10.1007/s10639-012-9188-x

\section{Appendix: Questionnaire}

Reading

1). What are the primary reasons that you read books? Please mark as many choices as apply.

Academic activities Knowledge enhancement Work-related information Entertainment Others, please specify:

2). How do you get books for reading? Please mark as many choices as apply. Buying Borrowing from a library Loaning from friends, etc. Free from online sources Others, please specify: 
3). Where do you prefer reading books? Please mark as many choices as apply.

Home
Library
Coffee houses
While traveling
At work
In front of a screen
Others, please specify

4). What type of books you read the most? Please mark as many choices as apply.

Fiction

Literary works other than fiction

Biographies

Best sellers

Recommended by others

S \& T

Art and culture

Socio-economic issues

Patriotic books

Fashion

Housekeeping

Hobbies

Travel and tourism

Others, please specify:

5). In which language do you read?

Arabic

English

Arabic and English

Others, please specify:

6). Do you read magazines?

Yes

No

If yes,

How many per week?

In which language?

What is your source?

7). How do you assess your book-reading?

Most enjoyable

Quite enjoyable 
- Enjoyable

- Less enjoyable

- Least enjoyable

8). How often do you read books?

$\begin{array}{cl}\circ & \text { Most frequently } \\ \circ & \text { Frequently } \\ \circ & \text { Sometimes } \\ \circ & \text { Rarely } \\ \circ & \text { Never }\end{array}$

E-Reading

1) Do you read e-books?

Yes

No

2) If you read e-books, what device do you use?

- Dedicated e-book reader (Kindle, Sony, Nook, etc.)

- Other devices (mobile phone, iPad, etc.)

3) How often do you use the e-book reader?

○ Most frequently

○ Frequently

- Sometimes

- Rarely

- Never

4) How much reading do you do on an e-book reader?

○ All of my reading

- About two-thirds of my reading

- About a third of my reading

- Less than a third of my reading

- I read only a few books

5) What do you use your e-book reader for?

- Recreational reading

- Class reading

○ Work-related reading

O Other, please specify: 
6). What else you use the e-book reader for? (You may choose more than one answer)

- Fiction

- Course-related material (i.e., journal articles)

- Material to support my study from other sources (i.e., the internet)

- Documents created by myself

- Audio material other than podcasts

- Pictures and photos

Others, please specify:

7) Where do you usually use the e-book reader? (You can choose more than one answer).

- At home

- In a library

- In a coffee house/restaurant

○ At work

O Other places, please specify:

8) How do you get e-books? (Check all that apply):

a) Stores specific to the e-book reader (Amazon, Sony, e-Book Store, etc.)

b) Independent online retailers (BooksOnBoard, Ereader.com, etc.)

c) Open access repositories

d) Libraries

e) Other, please specify

9). How valuable are the following e-book features? Please indicate the value on a scale of 1 to 5 ( 1 being very valuable and 5 not valuable).

\section{$\begin{array}{lllll}1 & 2 & 3 & 4 & 5\end{array}$}
a). Portability
b). Convenience for acquiring books
c). Ability to store many books
d). Special functions (dictionary, internet access)
e). Text to speech capabilities
f). Access to a large collection
g). Other (please specify)

10). Which of the following shortcomings discourage the use of e-books? Indicate your agreement on a scale of 1 to 5 (1, completely agree and 5 , completely disagree).

$$
\begin{array}{lllll}
1 & 2 & 3 & 4 & 5
\end{array}
$$
a). Cost of e-readers
b). Cost of e-books
c). Eyestrain
d). Limited selection
e). Privacy concerns 
f). Preference for print

g). User interface

h). Other (please specify)

11). How helpful do you find e-books in your studies?

- Most helpful

- Quite helpful

- Helpful

○ Less helpful

- Least helpful

12). Please rate your overall satisfaction with e-books.
○ Most satisfied
○ Quite satisfied
- Satisfied
- Less satisfied
○ Least satisfied

13). If you are currently not reading e-books, would you be interested in reading e-books under the following circumstances? Please check all that apply.

- E-readers become available from the library.

- E-books are used as text reading.

- E-books become available free.

- E-reader features become more user-friendly.

- E-books provide clear instructions and information.

Other, please specify:

14). Would you like to acquire an e-book reader in the future?

- Yes, within a year or two

- Yes, before I graduate

- Yes, but not until I graduate

- Not sure

15). Please express any concerns or problems you have about e-books or e-readers not listed in the above questions:

\section{Copyrights}

Copyright for this article is retained by the author(s), with first publication rights granted to the journal.

This is an open-access article distributed under the terms and conditions of the Creative Commons Attribution license (http://creativecommons.org/licenses/by/4.0/). 